\title{
Health Related Quality of Life and Cognitive Decline in Older Populations: Preliminary Results From NeuroDemeNPsia Study
}

Journal of Applied Gerontology

2020, Vol. 39(6) 618-626

(C) The Author(s) 2019

Article reuse guidelines:

sagepub.com/journals-permissions

DOI: I0.I I77/07334648|9866587

journals.sagepub.com/home/jag

(S)AGE

\author{
Iban Onandia-Hinchado' and Unai Diaz-Orueta ${ }^{2}$
}

\begin{abstract}
Goal: To measure Health Related Quality of Life (HRQoL) in people with different primary degenerative dementias and compare them with 50+ years old older individuals with mild cognitive impairment (MCl) and healthy controls (HCs). Materials and Methods: In all, 45 participants suffered from Alzheimer's disease (AD) dementia, 27 from Lewy body dementia (LBD), I7 from frontotemporal dementia (FTD), 43 from MCl, and $3 \mathrm{I} \mathrm{HCs}(n=163)$. The I2-Item Short Form Health Survey, version 2 (SF-I2-v2) and Mini Mental State Examination were administered. Reisberg's Global Deterioration Scale (GDS) was completed by a neurologist. HRQoL indices obtained via the SF-I2-v2 were compared between different subgroups. Results: Physical Function, Physical Role, Emotional Role, and Physical Summary Composite scores showed the best scores for patients with $\mathrm{AD}$, followed by $\mathrm{HC}$ and $\mathrm{MCl}$, and finally FTD and LBD. Discussion: A differentiated profile in HRQoL is shown in dementia subgroups, and may be useful to support differential diagnosis.
\end{abstract}

\section{Keywords}

dementia, caregiving, assessment, health related quality of life

\section{Introduction}

Dementia constitutes a group of disorders with a great heterogeneity in terms of etiology, behavior, insight, judgment, and other symptoms such as psychosis, anxiety, or depression (Banerjee et al., 2009). The World Health Organization defines Health Related Quality of Life (HRQoL) as the personal perception about one's own life position in terms of achievements, expectations, standards, and concerns (Sartorius, 1990). A recent meta-analysis including more than 37,000 patients with dementia of various etiologies showed the relevance of HRQoL and, at the same time, linked reported HRQoL to a wide range of variables that have to be explored further (Martyr et al., 2018). According to Landeiro et al. (2018), HRQoL is increasingly recognized as an important outcome measure in dementia research, and a detailed level of measurement and assessment will help improve information on disease progression and cost-effectiveness models in this area. To date, a majority of studies conducted in this area have focused on the conceptual analysis of HRQoL in dementia, as well as on the study of psychometric properties of dedicated assessment instruments (Banerjee et al., 2009).
Although these assessment tools were developed recently, some have already shown evidence for the relationship between HRQoL and clinical variables such as cognition, limitations in daily life activities, behavioral disorders, depression, or caregiver burden (Banerjee et al., 2009). As a consequence and due to the range of symptoms shown in dementia syndromes, there is an increasing consensus with regard to the need of considering HRQoL with the same relevance as cognition and behavior (Rabins \& Black, 2007; Whitehouse, 2000). Difficulties arise from the way HRQoL information is collected, as the test-taker may show better or worse communication abilities when self-reporting about their own HRQoL, and may be willing to show compliance with the evaluator (Wlodarzcyk, Brodaty, \& Hawthorne,

Manuscript received: January 29, 2019; final revision received: July 3, 2019; accepted: July 9, 2019.

'University of the Basque Country, Donostia-San Sebastian, Spain

${ }^{2}$ Maynooth University, Ireland

Corresponding Author:

Unai Diaz-Orueta, Department of Psychology, Maynooth University, Maynooth, Co. Kildare, W23 F2H6, Ireland.

Email: unai.diazorueta@mu.ie 
2004). However, despite difficulties with assessment, measures of HRQoL may help not only when assessing the impact of the disease on patients but also when it comes to clarifying and demonstrating objective intervention effects.

Concerns exist in relation to the use of generic quality of life measures when assessing individuals with dementias, as these generic instruments have not been specifically validated for these samples (Ettema, Dröes, de Lange, Mellenbergh, \& Ribbe, 2005; Silberfeld, Rueda, Krahn, \& Naglie, 2002). In fact, in the last 10 to 15 years, knowledge in the area has increased, so that studies now show that HRQoL data may be obtained by means of both subjective reports and proxy measures (Brod, Stewart, Sands, \& Walton, 1999; Logsdon, Gibbins, McCurry, \& Teri, 2002; Smith et al., 2005). Instruments developed so far are quick and easy to administer to a wide heterogeneous variety of cases (Banerjee et al., 2009). The National Institute for Health and Care Excellence (NICE; 2006) shows the relevance of improvement in HRQoL when intervening in dementias. Other authors (Small et al., 1997; Winblad et al., 2001) had previously observed the importance of redefining the treatment success to incorporate additional parameters of the patient's lifestyle, such as daily life activities, behavioral disorders, caregiver burden, HRQoL, or usage of existing resources in the community. Schwartz (2013) emphasized the need for these measures, not only in the design of services required by an individual with cognitive decline in the face of institutionalization in a nursing home but also in relation to its utility when establishing treatment priorities. For this reason, some criteria must be fulfilled, such as a score higher than 10 in the Mini Mental State Examination (MMSE) general cognitive screening test (Folstein et al., 1975), although the scoring in this test does not seem to correlate with either HRQoL self-perception or with caregivers' reports (Fuh \& Wang, 2006; Logsdon et al., 2002; Vogel, Mortensen, Hasselbalch, Andersen, \& Waldemar, 2006). Age may also influence the level of HRQoL in dementia patients (Banerjee et al., 2006).

According to reports from both formal and informal caregivers, HRQoL is influenced by the presence of behavioral disorders, but this relationship is not observed in patients' reports, which show a differential impact from these behavioral disorders or even a decrease in awareness and insight (Banerjee et al., 2009; Banerjee et al., 2006; Hoe, Hancock, Livingston \& Orrell, 2006; Logsdon et al., 2002). HRQoL is also likely to be modulated by mood disorders (Logsdon et al., 2002; Smith et al., 2005), depression, and anxiety (Banerjee et al., 2006), so that an improvement in HRQoL may relate to an improvement in depression and communication skills (Woods, Thorgrimsen, Spector, Royan, \& Orrell, 2006). Scores in patients' self-reported HRQoL can be predicted by depression and anxiety (34\% of the variance), while professional caregivers' opinion is only linked to behavioral disorders (43\% of the variance) (Banerjee et al., 2006; Hoe et al., 2006; Samus et al., 2006; Samus et al., 2005; Thomas et al., 2006). Effects of these variables are not causal, but they maintain over time and have an impact on the decrease of HRQoL. In a longitudinal study by Lyketsos et al. (2003) on reports given by patients' proxies over time, scores decrease after a 2-year follow-up, with a Cohen's $d$ effect of .36, while half of the study subjects did not suffer any change or even improved, thus showing evidence that even with a progression of dementia, HRQoL does not necessarily decay. The only predictor found was the baseline HRQoL score.

Based on caregivers' reports, autonomy in Daily Life Activities, both basic and instrumental, has an effect on HRQoL, sometimes an effect even higher than the impact of cognitive decline (Karlawish, Lu, Logsdon, Whitehouse, \& Aisen, 2004). When an early intervention takes place in this area, those with low baseline performance in Daily Life Activities may show significant improvement (Banerjee et al., 2007; Zimmerman et al., 2005). By means of the implementation of cognitive stimulation therapy on a group basis, some improvements in Daily Life Activities have been reported with regard to control groups (Spector et al., 2003), and maintaining this stimulation improved the performance from baseline to the post-intervention assessment; however, as MMSE scores declined, the HRQoL declined too (Orrell, Spector, Thorgrimsen, \& Woods, 2005). In terms of gender differences, women seem to benefit most from the intervention, while men without treatment perform worse (Woods et al., 2006).

In terms of differences between chronic conditions, dementia gets the best scores in HRQoL (as compared, by a way of example, with diabetes or other chronic conditions), but when sociodemographic variables are taken into account, dementia is the condition showing the largest decrease in HRQoL. Moreover, quality of life tends to decline with age, while dementia onset is also related to late-life ages (Esteban y Peña et al., 2010). However, there are no previous studies pointing to how different types of dementia, and, more specifically, primary degenerative dementias, may influence the HRQoL scores, or how HRQoL may constitute a relevant differential measure for the diagnosis of specific subtypes of dementia.

With this framework, the goal of the present study was to compare HRQoL of people with different types of dementia with healthy cognitive aging individuals, as well as to compare different HRQoL profiles among different subtypes of primary degenerative dementias. It was hypothesized that different HRQoL profiles would be found between dementia groups and controls, and between the different dementia subtypes.

\section{Method}

The study comprised an incidental sample of 163 participants divided into five groups: (a) 45 individuals with a diagnosis of Alzheimer's disease (AD) dementia, (b) 27 individuals with a diagnosis of Lewy body dementia (LBD), (c) 17 individuals with frontotemporal dementia (FTD), and 
(d) 43 individuals with a diagnosis of mild cognitive impairment (MCI). Moreover, a control group was available: (e) 31 individuals with no cognitive decline, namely, healthy controls (HCs). Individuals who attended a neurology clinic and fulfilled the inclusion criteria were invited to voluntarily participate in the NeuroDemeNPsia study, in which crosssectional measures of psychological and neuropsychological variables were taken, so the final sample and group sizes were shaped based on the availability of suitable participants. Inclusion criteria included the following:

1. Cognitive decline due to a degenerative primary dementia (AD, LBD, or FTD; with scores in the Reisberg et al.'s Global Deterioration Scale [GDS] of 3 or 4 ) or due to a MCI but not dementia. Those scoring 1 or 2 in the GDS and showing a regular cognitive performance (not above or below 2 standard deviations from the mean in cognitive tests) were included as $\mathrm{HC}$;

2. Individuals with a diagnosis of $\mathrm{AD}$ had to fulfill National Institute of Neurological and Communicative Disorders and Stroke and the Alzheimer's Disease and Related Disorders Association (NINCDSADRDA) diagnostic criteria (Dubois et al., 2007); those with LBD had to fulfill Dementia With Lewy Bodies (DLB) International Workshop diagnostic criteria (McKeith et al., 2005); and those with FTD had to fulfill the criteria from the Work Group Frontotemporal Dementia and Pick's Disease (McKhann et al., 2001).

3. Individuals with MCI had to fulfill criteria from the Spanish Neurological Society (SEN; Robles, Del Ser, Alom, Peña Casanova, \& Grupo Asesor del Grupo de Neurología de la Conducta y Demencias de la Sociedad Española de Neurología, 2002) and a score of 3 in the GDS;

4. All received a diagnosis by a neurologist from a primary care setting in the Greater Bilbao area (Spain);

5. All signed a consent form, with explicit authorization to participate given by the individual and, where required, from their caregiver.

Exclusion criteria followed in this study included the following: (a) suffering from conditions associated to decline in intellectual functions, such as cerebral infections, stroke, encephalic degenerative diseases, psychiatric disorders, or showing conditions affecting functionality to prevent their participation in the study (deafness, blindness, etc.), all of it confirmed by the clinical record and a check-up by a neurologist, and (b) those lacking a companion or informal caregiver who may respond as the main caregiver were also excluded.

HRQoL is measured by means of the 12-Item Short Form Health Survey, version 2 (SF-12-v2) questionnaire, developed by Ware, Kosinski, Turner-Bowker, and Gandek (2002). It comprises 12 items whose goal is to easily gather information about the level of well-being and functional capacity of an individual, defining positive and negative status of both physical and mental health by means of eight factors or subscales (Physical Function, Physical Role, Body Pain, General Health, Vitality, Social Function, Emotional Role, and Mental Health) and two summary composite measures (physical [PSC] and mental [MSC]). Some items read, "In general, would you say your health is ...." "During the past 4 weeks, have you had any of the following problems with your regular daily activities ...." or "During the past 4 weeks, how much did pain interfere ...?" Response options are presented in a Likert-type scale (with options ranging from 3 to 6 points, depending on the item), which evaluate intensity and/or frequency of individual's health status. Scoring ranges from 0 to 100 , where higher scores mean a better HRQoL. Research on this scale has shown internal consistency scores higher than 0.70 , and significant correlations between the different versions of the scale (Jenkinson \& Layte, 1997).

This measure was selected (in the absence of dementiaspecific HRQoL measures) as it was the most widely used measure for HRQoL. Both patient's and an informant's (i.e., relative or main caregiver) questionnaires were collected for all the groups (dementia, MCI, and HC). In this case, the informants needed to answer the questions as if they were the patients themselves.

Norms and weights from the American version were used in the absence of a full validation of the scale with a representative older Spanish population at the time of the study. The questionnaire itself had already been validated to Spanish by other authors for a wider age range, with a younger, general population-based sample (Monteagudo, Hernando, \& Palomar, 2011). Estimation of dimensions and summary composite scores was performed by means of the standard method that uses an algorithm with the mean scores, standard deviations, and factorial weights in the general population (Ware et al., 2002), leading to comparable typified scores. Validity coefficients (test-retest) were 0.89 and 0.76 for PSC and MSC, respectively. In addition, the MMSE was administered as a measure of global cognitive function.

\section{Results}

\section{Sociodemographic and Clinical Features}

Sociodemographic variables for each of the groups can be seen in Table 1. The MCI group was the youngest, while the highest mean age corresponds to the LBD group, followed by the AD group. There were no statistically significant age differences between dementia subgroups, and only when compared with the MCI group, these differences appeared, which seems to adhere to the logic of the MCI being a preclinical anterior state to the development of different types of dementia (Feldman \& Jacova, 2005; Feldman \& Kandiah, 2008; Gabryelewicz et al., 2007; Lambon, Patterson, Graham, Dawson, \& Hodges, 2003; Petersen et al., 2001). 
Table I. Sociodemographic Features of the Sample.

\begin{tabular}{|c|c|c|c|c|c|c|c|}
\hline & $\mathrm{AD}(n=45)$ & $\operatorname{LBD}(n=27)$ & FTD $(n=17)$ & $\mathrm{MCl}(n=43)$ & $\mathrm{HC}(n=3 \mathrm{I})$ & $\begin{array}{c}\text { Statistics } \\
\text { (chi-square test) }\end{array}$ & $p$ \\
\hline \multicolumn{8}{|l|}{ Sex } \\
\hline Male N (\%) & $20(44)$ & $13(48)$ & $8(47)$ & $14(33)$ & $9(29)$ & $\chi^{2}(4)=4.005$ & .405 \\
\hline \multirow[t]{2}{*}{ Female $N(\%)$} & $25(56)$ & $14(52)$ & $9(53)$ & $29(67)$ & $22(7 I)$ & & \\
\hline & & & & & & $\begin{array}{c}\text { Statistics } \\
\text { (Kruskal-Wallis } \\
H \text { test) }\end{array}$ & $p$ \\
\hline \multicolumn{8}{|l|}{ Age $(M \pm S D)$} \\
\hline All groups & $\begin{array}{l}77.18 \pm 6.27 \\
(56-90 \text { years })\end{array}$ & $\begin{array}{l}78.26 \pm 7.26 \\
(59-89 \text { years })\end{array}$ & $\begin{array}{l}74.35 \pm 8.32 \\
(53-83 \text { years })\end{array}$ & $\begin{array}{l}70.77 \pm 11.49 \\
(54-85 \text { years })\end{array}$ & $\begin{array}{c}75 \pm 6.67 \\
(62-91 \text { years })\end{array}$ & $\chi^{2}(4)=|3.37|$ & .010 \\
\hline $\begin{array}{l}\text { Dementia groups vs. } \\
\text { control }\end{array}$ & & & & - & & $\chi^{2}(3)=6.666$ & .083 \\
\hline Dementia groups & & & & - & - & $\chi^{2}(2)=2.204$ & .332 \\
\hline $\begin{array}{l}\text { Groups with cognitive } \\
\text { decline }\end{array}$ & & & & & - & $\chi^{2}(3)=11.338$ & .010 \\
\hline \multicolumn{8}{|c|}{ Years of education $(M \pm S D)$} \\
\hline All groups & $6.21 \pm 3.48$ & $7.72 \pm 2.95$ & $8.93 \pm 4.62$ & $9.67 \pm 5.35$ & $8.35 \pm 3.35$ & $\chi^{2}(4)=12.314$ & .015 \\
\hline $\begin{array}{l}\text { Dementia groups vs. } \\
\text { control }\end{array}$ & & & & - & & $\chi^{2}(3)=6.179$ & .013 \\
\hline Dementia groups & & & & - & - & $\chi^{2}(2)=4.947$ & .084 \\
\hline $\begin{array}{l}\text { Groups with cognitive } \\
\text { decline }\end{array}$ & & & & & - & $\chi^{2}(3)=11.932$ & .008 \\
\hline
\end{tabular}

Note. $\mathrm{AD}=$ Alzheimer's disease; LBD = Lewy body dementia; FTD = frontotemporal dementia; $\mathrm{MCl}=$ mild cognitive impairment; $\mathrm{HC}=$ healthy controls.

In terms of gender, no statistically significant differences were observed between groups. In terms of years of education, the $\mathrm{AD}$ patients group shows the lowest score, followed by LBD, HC, FTD, and, finally, MCI group. The mean years for all the groups is $8.07(S D=4.35)$, in a range from 0 to 22 years of formal education, with a majority of individuals ranging from 6 to 12 years.

Table 2 shows the clinical features of the groups assessed, those having different neurodegenerative diseases, MCI, and HCs.

A comparison was performed between the level of functional decline as measured by the GDS (Reisberg, Ferris, de Leon, \& Crook, 1982) and belonging to a specific group. Thus, a statistically significant interaction was observed between the group (i.e., dementia, MCI, HC) and the level of functional decline $\left(\chi^{2}=187.864 ; p=.000\right)$, with the $\mathrm{AD}$ group showing the highest percentage of patients within some level of functional decline, and significantly worse than those with LBD and FTD.

One of the key scores depicted in Table 2 is the amount of time since the appearance of first symptoms, as it may explain part of the variance of both psychiatric symptomatology and neuropsychological performance. No statistically significant differences were found between the three groups with dementia, neither when the fourth group with MCI was included in the analysis.
In terms of differences between MMSE scores, there were no statistically significant differences between the three dementia groups, and as expected, significant differences were found between these and the groups with MCI and HC. Moreover, significant differences appear between the MCI and $\mathrm{HC}$ groups $(U=294 ; p=.000)$. Using a qualitative group categorization for the MMSE based on cut-points for absence of cognitive decline (score $\geq 24$ ), mild cognitive disorder (score from 18 to 23), and severe cognitive disorder (score from 0 to 17), differences were observed across all groups in terms of severity of cognitive decline distribution.

Interestingly, a correlation analysis between clinical and sociodemographic variables showed that there was a clear cohort effect in this sample (i.e., Spanish post-Civil War generation with lower access to education), because years of education and age showed a highly significant inverse correlation $(r=-.372, p<.01)$. Similarly, global cognitive status was related, to some extent, to years of clinical development (i.e., time since the first symptoms appeared; GDS vs. years since first symptoms: $r=.442, p<.01$; MMSE score vs. years since first symptoms: $r=-.273, p<.01)$.

\section{HRQoL Among Groups}

Supplemental Table 1 shows the results for the SF-12-v2, administered both to participants and proxies (i.e., relatives or 
Table 2. Clinical Features of the Sample.

\begin{tabular}{|c|c|c|c|c|c|c|c|}
\hline Clinical variables & $\mathrm{AD}(n=45)$ & $\operatorname{LBD}(n=27)$ & FTD $(n=17)$ & $\mathrm{MCl}(n=43)$ & $\mathrm{HC}(n=3 \mathrm{I})$ & $\begin{array}{c}\text { Statistics } \\
\text { (Kruskal-Wallis } H \text { test) }\end{array}$ & $p$ \\
\hline \multicolumn{8}{|l|}{ GDS score $(M \pm S D$; range) } \\
\hline Dementia groups & & & & - & - & $\chi^{2}(2)=5.164$ & .076 \\
\hline Groups with cognitive decline & $3.73 \pm 0.75$ & $3.35 \pm 0.49$ & $3.76 \pm 1.03$ & $3.05 \pm 0.58$ & - & $\chi^{2}(3)=23.717$ & $.000 *$ \\
\hline All groups & & & & & $1.1 \pm 0.3$ & $\chi^{2}(4)=97.265$ & $.000 *$ \\
\hline \multicolumn{8}{|l|}{ Qualitative Group Categorization GDS—N (\%) } \\
\hline No functional decline (I) & 0 & 0 & 0 & 0 & $28(90.3)$ & $\chi^{2}(4)=187.864$ & $.000 *$ \\
\hline Very mild functional decline (2) & I (2.2) & 0 & I (5.9) & $5(11.6)$ & $3(9.7)$ & & \\
\hline Mild functional decline (3) & $16(35.6)$ & $17(63)$ & $7(4 \mid .2)$ & $32(74.4)$ & 0 & & \\
\hline Moderate functional decline (4) & $23(51.1)$ & $9(33.3)$ & $5(29.4)$ & $5(11.6)$ & 0 & & \\
\hline Moderate to severe functional decline (5) & $4(8.9)$ & 0 & $3(17.6)$ & I (2.3) & 0 & & \\
\hline Severe functional decline (6) & I (2.2) & 0 & I (5.9) & 0 & 0 & & \\
\hline Very severe functional decline (7) & 0 & I (3.7) & 0 & 0 & 0 & & \\
\hline \multicolumn{8}{|l|}{ Years since symptoms started $(M \pm S D)$} \\
\hline Dementia groups & $4.44 \pm 2.65$ & $3.59 \pm 2.49$ & $4.31 \pm 2.80$ & - & - & $\chi^{2}(2)=2.238$ & .327 \\
\hline Groups with cognitive decline & & & & $4.31 \pm 2.76$ & - & $\chi^{2}(3)=2.347$ & .504 \\
\hline \multicolumn{8}{|l|}{ MMSE scores $(M \pm S D)$} \\
\hline Dementia groups & & & & - & - & $\chi^{2}(2)=3.744$ & .154 \\
\hline Groups with cognitive decline & $19.71 \pm 4.20$ & $21.15 \pm 5.43$ & $20.71 \pm 5.61$ & $25.12 \pm 3.41$ & - & $\chi^{2}(3)=33.976$ & $.000 *$ \\
\hline All groups & & & & & $28.03 \pm 1.33$ & $\chi^{2}(4)=79.996$ & $.000 *$ \\
\hline \multicolumn{8}{|l|}{ Qualitative MMSE (based on cut-points) } \\
\hline No cognitive decline $(\geq 24)$ & $10(22.2)$ & II (40.7) & $7(41.2)$ & $32(74.4)$ & $31(100)$ & $\chi^{2}(8)=58.762$ & $.000 *$ \\
\hline Mild cognitive disorder (18-23) & $20(44.4)$ & $12(44.4)$ & $6(35.3)$ & $9(20.9)$ & - & & \\
\hline Severe cognitive disorder $(0-17)$ & $15(33.3)$ & $4(14.8)$ & $4(23.5)$ & $2(4.7)$ & - & & \\
\hline
\end{tabular}

Note. $A D=$ Alzheimer's disease; LBD = Lewy body dementia; FTD = frontotemporal dementia; $\mathrm{MCl}=$ mild cognitive impairment; $\mathrm{HC}=$ healthy controls; GDS = Global Deterioration Scale; MMSE = Mini Mental State Examination.

$* p<.05$

caregivers), while Supplemental Table 2 shows post hoc analyses comparing intergroup differences in HRQoL (as selfreported by participants) and Supplemental Table 3 the post hoc analyses for intergroup differences based on proxies' reports. Statistical comparisons carried out between the "patient rated" and the "relative rated" administrations of the HRQoL have been published elsewhere (Onandia-Hinchado \& Diaz-Orueta, 2019) and show a high level of agreement between patients' and proxies' reports, even higher than between HCs' and proxies' reports.

In terms of self-reported Physical Function, dementia subgroups differed significantly. Post hoc analysis showed that LBD participants showed significantly lower scores than all the other groups, except with the FTD group, and these scores were consistent between self-reported measures and those reported by proxies. Additional linear regression analysis performed to rule out the influence of age, gender, years with symptoms, and years of education did not show any influence on Physical Function, neither for patients' or for proxies' reports.

Analysis of self-reported Physical Role showed significant differences between groups with dementia alone, groups with cognitive decline (dementia and MCI), and across all groups. Highest scores, as expected, were shown by HCs, followed very closely by those with $\mathrm{AD}$. Lowest scores were for the LBD and FTD subgroups. Post hoc Mann-Whitney $U$ analyses for self-reported measures showed statistically significant differences between $\mathrm{AD}$ and LBD (mean ranks 30.83 vs. 19.58), $\mathrm{AD}$ and $\mathrm{MCI}$ (37.72 vs. 29.53), and LBD and $\mathrm{HC}$ (16.95 vs. 25.64). Consideration of proxies' reports for the Physical Role ratings showed significant differences again not only between AD and LBD (34.80 vs. 21.31) but also between AD and FTD (29.01 vs. 17.19), FTD and HC (14.88 vs. 25.69), and for LBD scoring significantly lower than all the other groups except FTD, which raises issues about the impact of LBD in caregivers' burden. In a linear regression analysis, no sociodemographic variables showed any significant effect on the variance of the Physical Role scores.

Body Pain only showed differences for self-reported measures between AD and LBD patients (29.88 vs. 22.62), while proxies' reports did not show any statistically significant differences. Scherder, Sergeant, and Swaab (2003) reported that patients with $\mathrm{AD}$ experience greater pain due to such factors as the presence of white-matter lesions, while there is a lack of experimental data on pain in other subtypes of dementia such as LBD.

In terms of General Health, once again, LBD patients showed statistically significant lower scores than all the other groups except FTD, and also between FTD and HC (12.00 vs. 20.50), according to self-reports. According to proxies, significant lower scores were present for LBD compared with HC (19.74 vs. 31.08), and FTD compared with HC (16.12 vs. 25.18).

For Vitality, post hoc analyses showed statistically significant differences in favor of AD (38.73) when compared with MCI patients (29.67) only in self-reported measures, 
and both participants and proxies were consistent in reporting differences between MCI and HC (25.41 vs. 34.70 according to participants; 29.39 vs. 41.87 according to proxies). Interestingly, Vitality is the only measure in which HC showed statistically higher scores than all the other groups, according to proxies' reports.

For Social Function, no statistically significant differences were reported, either by the participants themselves or by proxies.

Emotional Role showed significantly higher scores for $\mathrm{AD}$ when compared with $\mathrm{HC}$ only in participants' reports (30.52 vs. 23.11), and between LBD and HC both in selfreports (18.45 vs. 23.20) and proxies' reports (20.98 vs. 30.24).

In terms of Mental Health, the only statistically significant differences were based on caregivers' reports, showing that the HC score was significantly higher than LBD, FTD, and MCI.

When performing a further analysis of summary composite scores, the PSC showed consistent statistically significant differences both from patients' and caregivers' perspective. In both cases, patients with $\mathrm{AD}$ showed the highest scores, followed by HC and MCI, and, finally, those with FTD and LBD (FTD ranking the last from patients' perspective and LBD ranking the last from caregivers' perspective). Post hoc analyses showed statistically significant differences, both in patients' and proxies' reports, between $\mathrm{AD}$ and LBD (participants: 30.28 vs. 18.79 ; proxies: 35.39 vs. 20.24 ), AD and FTD (participants: 24.86 vs. 16.21 ; proxies: 28.53 vs. 18.62 ), and LBD and HC (participants: 15.47 vs. 25.77; proxies: 19.67 vs. 31.13). Linear regression analysis showed no influence of age, years of education, or years since first symptoms appeared.

Finally, for the MSC score, significant differences were only reported by caregivers, showing that HCs' score was significantly higher than $\mathrm{AD}, \mathrm{FTD}$, and $\mathrm{MCI}$.

\section{Discussion}

Differences in HRQoL, both in terms of self-perception and perception by informants, were observed across all dementia subgroups. Interestingly, there is a clear trend pointing to patients with LBD, followed by those with FTD, as the ones showing the lowest rates of HRQoL across most of the domains, which may be related to a higher prevalence of associated neuropsychiatric symptoms in these two conditions. In other words, results also show that dementias do not imply just cognitive deterioration but also a clear physical decline, which may be reinforced with existing comorbidities. Interestingly, patients with AD rated similarly to HCs (sometimes even higher) - both on self-report and by proxy report. This may be due to the fact that the sample shows a mild to moderate cognitive decline, still with enough ability to overcompensate, dissimulate, or even not to accept the pathology they suffer in an incipient and moderate level (Antoine, Nandrino, \& Billiet, 2013). Patients may neglect or minimize the impact of $A D$, mainly neglecting memory deficits (Jurado, Mataró, \& Pueyo, 2013; Sevush \& Leve, 1993), but also due to lack of disease awareness (anosognosia), which is the reason why they attend healthcare services when they are brought to them by relatives (Lipton \& Weiner, 2005). As a consequence, reports given by the patients themselves can be very relevant, but it is necessary to combine the information the individual provides with the information provided by a proxy, to better adjust the self-rating performed by the patient. In our study, consideration of an informant's report led to significant differences between groups that were not initially observed based solely on patients' self-reports.

In addition, some specific profiles of HRQoL may appear in dementia subtypes, especially in LBD, where the lowest scores are found, probably due to more limiting physical symptoms (McKeith et al., 2005). Differential profiles have also been identified in relation to cognitive decline. Age may have a unique effect in dementia, modifying scores for HRQoL (Banerjee et al., 2006), and gender also generates differences, especially in mental health, according to Woods et al. (2006). However, age, gender, years of education, or years since the first symptoms appeared did not seem to have an influence for the samples analyzed in this study. As a limitation, the sample of this study shows a cohort effect by means of which the higher the age, the lower the level of education, which may have affected our results to some extent.

In contrast, cognitive decline itself provokes a substantial decrease in HRQoL, as individuals with MCI also show a significant decrease of these scores (below HCs), especially in the MSC score (i.e., Mental Health), which allows targeting of people with incipient cognitive decline as early as possible to prevent comorbid mental health issues. The reason why so many statistically significant differences were shown in favor of individuals with an established diagnosis of $\mathrm{AD}$ (who tended to obtain higher scores), when compared with individuals with MCI, may be paradoxical, unless we consider that individuals with MCI may be more concerned about the progress of their health status and express that concern more realistically than individuals with established AD, who may overcompensate or even show less awareness of their actual status. To what extent a potential overestimation of HRQoL could be a marker for the progress from MCI to AD needs further research. In addition, HRQoL estimations seem to clearly differentiate between $\mathrm{AD}$ and other dementias, especially LBD and FTD.

Limitations of this study are clear. In terms of the HRQoL questionnaire used, at the time of data collection, there were no normative data for the Spanish population, which explains why the American version translated to Spanish was used instead, thus leading to a more cautious interpretation of obtained data. Moreover, the sample recruited was incidental, based on individual patients who attended a neurology 
consultation unit over the course of a year, which may impact the external generalizability of the results obtained here (especially, with regard to participants from smaller size dementia subgroups). With regard to this, in the particular case of individuals with FTD, no specific subgroup distinction was made between FTD subtypes, but, instead, every patient attending with an FTD diagnosis was included, due to the available small sample size. As GDS scores ranged from 3 to 4 , it was expected that language-related disorders were in very early stages and not significantly affecting patientreported HRQoL rates, as could be expected in FTD patients in more advanced stages. In addition, specific cohort effects related to an average low educational level of participants not only may limit comparisons with other samples with higher education levels but may also open the door to further consider the level of education as a mediating variable in HRQoL.

Further studies with larger, more representative samples and with dedicated, norm-based measures for HRQoL are required, but this study opens the door to a significant further consideration of HRQoL in populations with cognitive decline, also when developing intervention programs that focus both on cognitive and functional outcomes. Additional samples including vascular and other causes for dementia could also help us establish the real value of HRQoL as an additional complementary measure both for differential diagnosis and for the establishment of differential treatment targets in the biopsychosocial sphere of each patient.

\section{Acknowledgments}

Authors would like to thank Dr. Juan Mari Uterga from Basurto Hospital (Bilbao, Spain) for all his dedication to facilitate the work in the NeuroDemeNPsia Project and, especially, in the recruitment and provision of the sample of both clinical and healthy participants. They also thank Prof. Teresa Burke from Dublin City University (Dublin, Ireland) for her valuable comments and critical review of this work.

\section{Declaration of Conflicting Interests}

The author(s) declared no potential conflicts of interest with respect to the research, authorship, and/or publication of this article.

\section{Ethical Approval}

This study was linked to the achievement of the $\mathrm{PhD}$ by the first author, Dr. Onandia-Hinchado, at the University of Deusto in Bilbao (Spain). The study fulfilled all the ethical requirements and obtained the required ethical approval from the University of Deusto, Bilbao, Spain.

\section{Funding}

The author(s) disclosed receipt of the following financial support for the research, authorship, and/or publication of this article: This study was performed with a grant from the Basque Health Innovation and Research Foundation (BIOEF) for the first author, reference number BIOEF10/007.

\section{ORCID iD}

Unai Diaz-Orueta (iD https://orcid.org/0000-0002-0349-8890

\section{Supplemental Material}

Supplemental material for this article is available online.

\section{References}

Antoine, P., Nandrino, J. L., \& Billiet, C. (2013). Awareness of deficits in Alzheimer's disease patients: Analysis of performance prediction discrepancies. Psychiatry and Clinical Neurosciences, 67, 237-244. doi:10.1111/pcn.12050

Banerjee, S., Samsi Kritika Petrie, C. D., Alvir, J., Treglia, M., Schwam, E. M., \& del Valle, M. (2009). What do we know about quality of life in dementia? A review of the emerging evidence on the predictive and explanatory value of disease specific measures of health related quality of life in people with dementia. International Journal of Geriatric Psychiatry, 24, 15-24. doi:10.1002/gps.2090

Banerjee, S., Smith, S. C., Lamping, D. L., Harwood, R. H., Foley, B., Smith, P., . . Knapp, M. (2006). Quality of life in dementia: More than just cognition. An analysis of associations with quality of life in dementia. Journal of Neurology, Neurosurgery and Psychiatry, 77, 146-148. doi:10.1136/jnnp.2005.072983

Banerjee, S., Willis, R., Matthews, D., Contell, F., Chan, J., \& Murray, J. (2007). Improving the quality of care for mild to moderate dementia: An evaluation of the Croydon Memory Service Model. International Journal of Geriatric Psychiatry, 22, 782-788. doi:10.1002/gps.1741

Brod, M., Stewart, A., Sands, L., \& Walton, P. (1999). Conceptualization and measurement of quality of life in dementia: The Dementia Quality of Life instrument (DQoL). The Gerontologist, 39, 25-35. doi:10.1093/geront/39.1.25

Dubois, B., Feldman, H. H., Jacova, C., DeKosky, S. T., BarbergerGateau, P., Cummings, J., . . . Scheltens, P. (2007). Research criteria for the diagnosis of Alzheimer's disease: Revising the NINCDS-ADRDA criteria. The Lancet Neurology, 6, 734-746. doi:10.1016/S1474-4422(07)70178-3

Esteban y Peña, M. M., Hernandez, V., Fernández, X., Gil de Miguel, A., Rodríguez, M., López de Andrés, A., \& JiménezGarcía, R. (2010). Self-perception of health status, mental health and quality of life among adults with diabetes residing in a metropolitan area. Diabetes \& Metabolism, 36, 305-311. doi:10.1016/j.diabet.2010.02.003

Ettema, T. P., Dröes, R. M., de Lange, J., Mellenbergh, G. J., \& Ribbe, M. W. (2005). A review of quality of life instruments used in dementia. Quality of Life Research, 14, 675-686. doi:10.1007/s11136-004-1258-0

Feldman, H. H., \& Jacova, C. (2005). Mild cognitive impairment. The American Journal of Geriatric Psychiatry, 13, 645-655. doi:10.1097/00019442-200508000-00003

Feldman, H. H., \& Kandiah, N. (2008). Early identification of Alzheimer's disease: What have we learned from mild cognitive impairment? CNS Spectrums, 13(Suppl. 3), 4-7. doi:10.1017/S1092852900017181

Folstein, M. F., Folstein, S. E., \& McHugh, P. R. (1975). "Minimental state". A practical method for grading the cognitive state of patients for the clinician. Journal of Psychiatric Research, 12, 189-198. 
Fuh, J., \& Wang, S. (2006). Assessing quality of life in Taiwanese patients with Alzheimer's Disease. International Journal of Geriatric Psychiatry, 21, 103-107. doi:10.1002/gps.1425

Gabryelewicz, T., Styczynska, M., Luczywek, E., Barczak, A., Pfeffer, A., Androsiuk, W., . . . Barcikowska, M. (2007). The rate of conversion of mild cognitive impairment to dementia: Predictive role of depression. International Journal of Geriatric Psychiatry, 22, 563-567. doi:10.1002/gps.1716

Hoe, J., Hancock, G., Livingston, G., \& Orrell, M. (2006). Quality of life of people with dementia in residential care homes. The British Journal of Psychiatry, 188, 460-464. doi:10.1192/bjp. bp. 104.007658

Jenkinson, C., \& Layte, R. (1997). Development and testing of the UK SF-12 (short form health survey). Journal of Health Services Research and Policy, 2, 14-18.

Jurado, M. A., Mataró, M., \& Pueyo, R. (2013). Neuropsicología de las enfermedades neurodegenerativas [Neuropsychology of neurodegenerative diseases]. Madrid, Spain: Síntesis.

Karlawish, J., Lu, M., Logsdon, R., Whitehouse, P., \& Aisen, P. (2004). How much do 12 month changes in cognition and function influence changes in mild to moderate $\mathrm{AD}$ patients and caregivers ratings of patient quality of life? Neurobiology of Aging, 25(Suppl. 2), 324.

Lambon, M., Patterson, K., Graham, N., Dawson, K., \& Hodges, J. (2003). Homogeneity and heterogeneity in mild cognitive impairment and Alzheimer's disease: A cross-sectional and longitudinal study of 55 cases. Brain, 126, 2350-2362. doi:10.1093/brain/awg236

Landeiro, F., Walsh, K., Ghinai, I., Mughai, S., Nye, E., Wace, H., . . Gray, A. M. (2018). Measuring quality of life of people with predementia and dementia and their caregivers: A systematic review protocol. BMJ Open, 8, Article e 019082. doi:10.1136/bmjopen-2017-019082

Lipton, A. M., \& Weiner, M. F. (2005). Diagnóstico diferencial. In M. F. Weiner \& A. M. Lipton (Eds.), Demencias. Investigación, diagnóstico y tratamiento [Dementias. Research, diagnosis and treatment]. Barcelona, Spain: Masson.

Logsdon, R. G., Gibbins, L. E., McCurry, S. M., \& Teri, L. (2002). Assessing quality of life in older adults with cognitive impairments. Psychosomatic Medicine, 64, 510-519.

Lyketsos, C. G., González-Salvador, T., Chin, J. J., Baker, A., Black, B., \& Rabins, P. (2003). A follow-up study of change in quality of life among persons with dementia residing in a long-term care facility. International Journal of Geriatric Psychiatry, 18, 275-281.

Martyr, A., Nelis, S. M., Quinn, C., Wu, Y., Lamont, R., Henderson, C., . . Clare, L. (2018). Living well with dementia: A systematic review and correlational meta-analysis of factors associated with quality of life, well-being and life satisfaction in people with dementia. Psychological Medicine, 48, 2130-2139. doi:10.1017/S0033291718000405

McKeith, I. G., Dickson, D. W., Lowe, J., Emre, M., O'Brien, J. T., Feldman, H., . . . Consortium on DLB. (2005). Diagnosis and management of dementia with Lewy Bodies: Third report of the DLB Consortium. Neurology, 65, 1863-1872. doi:10.1212/01. wnl.0000187889.17253.b1

McKhann, G. M., Albert, M. S., Grossman, M., Miller, B., Dickson, D., \& Trojanowski, J. Q., \& Work Group on Frontotemporal
Dementia and Pick's Disease. (2001). Clinical and pathological diagnosis of frontotemporal dementia: Report of the Work Group on Frontotemporal Dementia and Pick's Disease. Archives of Neurology, 58, 1803-1809.

Monteagudo, O., Hernando, L., \& Palomar, J. A. (2011). Normas poblacionales de referencia de la versión española del SF-12V2 para la región de Murcia [Population based norms of the Spanish version of the SF-12V2 for Murcia (Spain)]. Gaceta Sanitaria, 25, 50-61.

National Institute for Health and Care Excellence. (2006). Donepezil, Galantime, Rivastigmine (Review) and Memantine for the treatment of Alzheimer's Disease (TAG 111). London, England: Author.

Onandia-Hinchado, I., \& Diaz-Orueta, U. (2019). Health Related Quality of Life in individuals with cognitive decline and discrepancies between patients and their proxies. Archives of Gerontology and Geriatrics. doi:10.1016/j.archger.2019.103914

Orrell, M., Spector, A., Thorgrimsen, S., \& Woods, B. (2005). A pilot study examining the effectiveness of maintenance cognitive stimulation therapy (MCST) for people with dementia. International Journal of Geriatric Psychiatry, 20, 446-451. doi:10.1002/gps.1304

Petersen, R. C., Doody, R., Kurz, A., Mohs, R. C., Morris, J. C., Rabins, P. V., . . . Winblad, B. (2001). Current concepts in mild cognitive impairment. Archives of Neurology, 58, 19851992. doi:10.1001/archneur.58.12.1985

Rabins, P. V., \& Black, B. (2007). Measuring quality of life in dementia: Purposes, goals, challenges and progress. International Psychogeriatrics, 19, 401-407. doi:10.1017/ S1041610207004863

Reisberg, B., Ferris, S. H., de Leon, M. J., \& Crook, T. (1982). Global Deterioration Scale for assessment of primary degenerative dementia. American Journal of Psychiatry, 139, 1136-1139.

Robles, A., Del Ser, T., Alom, J., Peña Casanova, J., . . G Grupo Asesor del Grupo de Neurología de la Conducta y Demencias de la Sociedad Española de Neurología. (2002). Propuesta de criterios para el diagnóstico clínico del deterioro cognitivo ligero, la demencia y la enfermedad de Alzheimer [Proposal of criteria for clinical diagnosis of mild cognitive impairment, dementia and Alzheimer's disease]. Neurología, 17, 17-32.

Samus, Q. M., Rosenblatt, A., Onyike, C., Steele, C., Baker, A., Harper, M., . . . Lyketsos, C. G. (2006). Correlates of caregiverrated quality of life in assisted living: The Maryland Assisted Living Study. The Journals of Gerontology: Psychological Science, 61, 311-314.

Samus, Q. M., Rosenblatt, A., Steele, C., Baker, A., Harper, M., Brandt, J., . . . Lyketsos, C. G. (2005). The association of neuropsychiatric symptoms and environment with quality of life in assisted living residents with dementia [Special issue]. The Gerontologist, 45(1), 19-26.

Sartorius, N. (1990). A WHO method for the assessment of healthrelated quality of life (WHOQoL). In S. Walker \& R. Rosser (Eds.), Quality of life assessment: Key issues in the 1990s (pp. 201-1207). Dordrecht, The Netherlands: Kluwer Academic Publishers.

Scherder, E. J., Sergeant, J. A., \& Swaab, D. F. (2003). Pain processing in dementia and its relation to neuropathology. The Lancet Neurology, 2, 677-686/. 
Schwartz, L. B. (2013). The importance of health-related quality of life in persons with cognitive impairment. Baltimore, MD: The John's Hopkins University.

Sevush, S., \& Leve, N. (1993). Denial of memory deficit in Alzheimer's disease. American Journal of Psychiatry, 150, 748-751. doi:10.1176/ajp.150.5.748

Silberfeld, M., Rueda, S., Krahn, M., \& Naglie, G. (2002). Content validity for dementia of three generic preference based health related quality of life instruments. Quality of Life Research, 11, 71-79. doi:10.1023/A:1014406429385

Small, G. W., Rabins, P. V., Barry, P. P., Buckholtz, N. S., Dekosky, S. T., Ferris, S. H., . . . Tune, L. E. (1997). Diagnosis and treatment of Alzheimer disease and related disorders: Consensus statement of the American Association for Geriatric Psychiatry, the Alzheimer's Association, and the American Geriatrics Society. The Journal of the American Medical Association, 278, 1363-1371. doi:10.1001/jama.1997.03550160083043

Smith, S. C., Lamping, D. L., Banerjee, S., Harwood, R., Foley, B., Smith, P., \& Knapp, M. (2005). Measurement of health-related quality of life for people with dementia: Development of a new instrument (DEMQOL) and an evaluation of current methodology. Health Technology Assessment, 9(10), 1-93. doi:10.3310/ hta9100

Spector, A., Thorgrimsen, S., Woods, B., Royan, L., Davies, S., Butterworth, M., \& Orrell, M. (2003). Efficacy of an evidencebased cognitive stimulation therapy programme for people with dementia: Randomised controlled trial. The British Journal of Psychiatry, 183, 248-254. doi:10.1192/03-23

Thomas, P., Lalloué, F., Preux, P. M., Hazif-Thomas, C., Pariel, S., Inscale, R., . . Clément, J. P. (2006). Dementia patients caregivers quality of life: The PIXEL study. International Journal of Geriatric Psychiatry, 21, 50-56. doi:10.1002/gps.1422
Vogel, A., Mortensen, E. L., Hasselbalch, S. G., Andersen, B. B., \& Waldemar, G. (2006). Patient versus informant reported quality of life in the earliest phases of Alzheimer's disease. International Journal of Geriatric of Psychiatry, 21, 11321138. doi:10.1002/gps.1619

Ware, J. E., Kosinski, M., Turner-Bowker, D. M., \& Gandek, B. (2002). How to score version 2 of the SF-12 health survey (with a supplement documenting version 1). Lincoln, RI: QualityMetric.

Whitehouse, P. J. (2000). Harmonization of dementia drug guidelines (United States and Europe): A report of the international working group for the harmonization for dementia drug guidelines. Alzheimer Disease and Association Disorders, 14(Suppl. 1), 119-122.

Winblad, B., Brodaty, H., Gauthier, S., Morris, J. C., Orgogozo, J. M., Rockwood, K., \& Wilkinson, D. (2001). Pharmacotherapy of Alzheimer's disease: Is there a need to redefine treatment success? International Journal of Geriatric Psychiatry, 16, 653-666. doi:10.1002/gps.496

Wlodarzcyk, J. H., Brodaty, H., \& Hawthorne, G. (2004). The relationship between quality of life, Mini-Mental State Examination, and the Instrumental Activities of Daily Living in patients with Alzheimer's Disease. Archives of Gerontology and Geriatrics, 39, 25-33. doi:10.1016/j.achger.2003.12.004

Woods, B., Thorgrimsen, S., Spector, A., Royan, L., \& Orrell, M. (2006). Improved quality of life and cognitive stimulation therapy in dementia. Aging Mental Health, 10, 219-226. doi:10.1080/13607860500431652

Zimmerman, S., Sloane, P. D., Williams, C. S., Reed, P. S., Preisser, J. S., Eckert, J. K., \& Dobbs, D. (2005). Dementia care and quality of life in assisted living and nursing homes [Special issue]. The Gerontologist, 45, 133-146. doi:10.1093/geront/45.suppl_1 